Supplement of Nonlin. Processes Geophys., 24, 113-123, 2017

http://www.nonlin-processes-geophys.net/24/113/2017/

doi:10.5194/npg-24-113-2017-supplement

(C) Author(s) 2017. CC Attribution 3.0 License.

(c) (i)

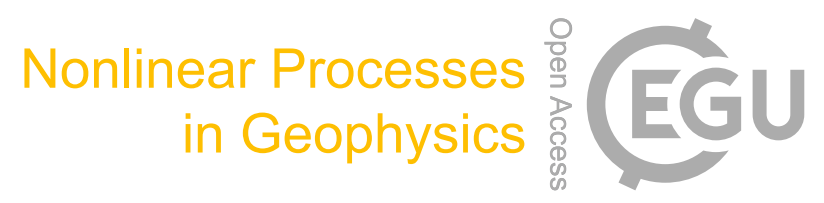

Supplement of

\title{
A matrix clustering method to explore patterns of land-cover transitions in satellite-derived maps of the Brazilian Amazon
}

Finn Müller-Hansen et al.

Correspondence to: Finn Müller-Hansen (mhansen@ pik-potsdam.de)

The copyright of individual parts of the supplement might differ from the CC-BY 3.0 licence. 
Table S1. Overview of land-cover classes in the TerraClass data set and assignment to simplified classes used in the paper.

\begin{tabular}{lll}
\hline TerraClass no. & TerraClass category & Simplified classes \\
\hline 01 & Annual crops & Annual crops \\
02 & Mosaic of uses & Other \\
03 & Urban area & Other \\
04 & Mining & Other \\
05 & Herbaceous pasture & Clean Pasture \\
06 & Shrubby pasture & Dirty Pasture \\
07 & Regeneration with Pasture & Dirty Pasture \\
08 & Pasture with exposed soil & Dirty Pasture \\
09 & Secondary Vegetation & Secondary Vegetation \\
10 & Others & Other \\
11 & Non-observed area & (Discarded) \\
12 & Reforestation & Other \\
13 & No forest (cerrado biome) & (Discarded) \\
14 & Primary forest & Forest \\
15 & Hydrography (rivers/lakes) & (Discarded) \\
16 & Recently deforested areas & Forest \\
\hline & & \\
\hline
\end{tabular}

Table S2. Markov transition matrix p as depicted in Fig. 3(a). If the rows do not sum up exactly to 1, this is due to rounding.

\begin{tabular}{lrrrrrr}
\hline TC2012 & Secondary Vegetation & Clean Pasture & Dirty Pasture & Forest & Annual Crops & Other \\
TC2010 & & & & & & \\
\hline Secondary Vegetation & 0.87 & 0.07 & 0.037 & 0 & 0.0038 & 0.019 \\
Clean Pasture & 0.026 & 0.84 & 0.11 & 0 & 0.018 & 0.009 \\
Dirty Pasture & 0.16 & 0.42 & 0.39 & 0 & 0.0066 & 0.03 \\
Forest & 0.0008 & 0.00091 & 0.0012 & 0.9987 & 0.00006 & 0.00031 \\
Annual Crops & 0.016 & 0.098 & 0.025 & 0 & 0.85 & 0.011 \\
Other & 0.15 & 0.17 & 0.14 & 0 & 0 & 0.54 \\
\hline
\end{tabular}


Table S3. Conditional transition matrix $\mathbf{q}$ as depicted in Fig. 3(b).

\begin{tabular}{lrrrrrr}
\hline TC2012 & Secondary Vegetation & Clean Pasture & Dirty Pasture & Forest & Annual Crops & Other \\
TC2010 & & & & & & \\
\hline Secondary Vegetation & - & 0.54 & 0.28 & 0 & 0.029 & 0.15 \\
Clean Pasture & 0.16 & - & 0.67 & 0 & 0.11 & 0.056 \\
Dirty Pasture & 0.26 & 0.68 & - & 0 & 0.011 & 0.05 \\
Forest & 0.25 & 0.28 & 0.36 & - & 0.019 & 0.097 \\
Annual Crops & 0.1 & 0.66 & 0.17 & 0 & - & 0.071 \\
Other & 0.32 & 0.37 & 0.31 & 0 & 0 & - \\
\hline
\end{tabular}
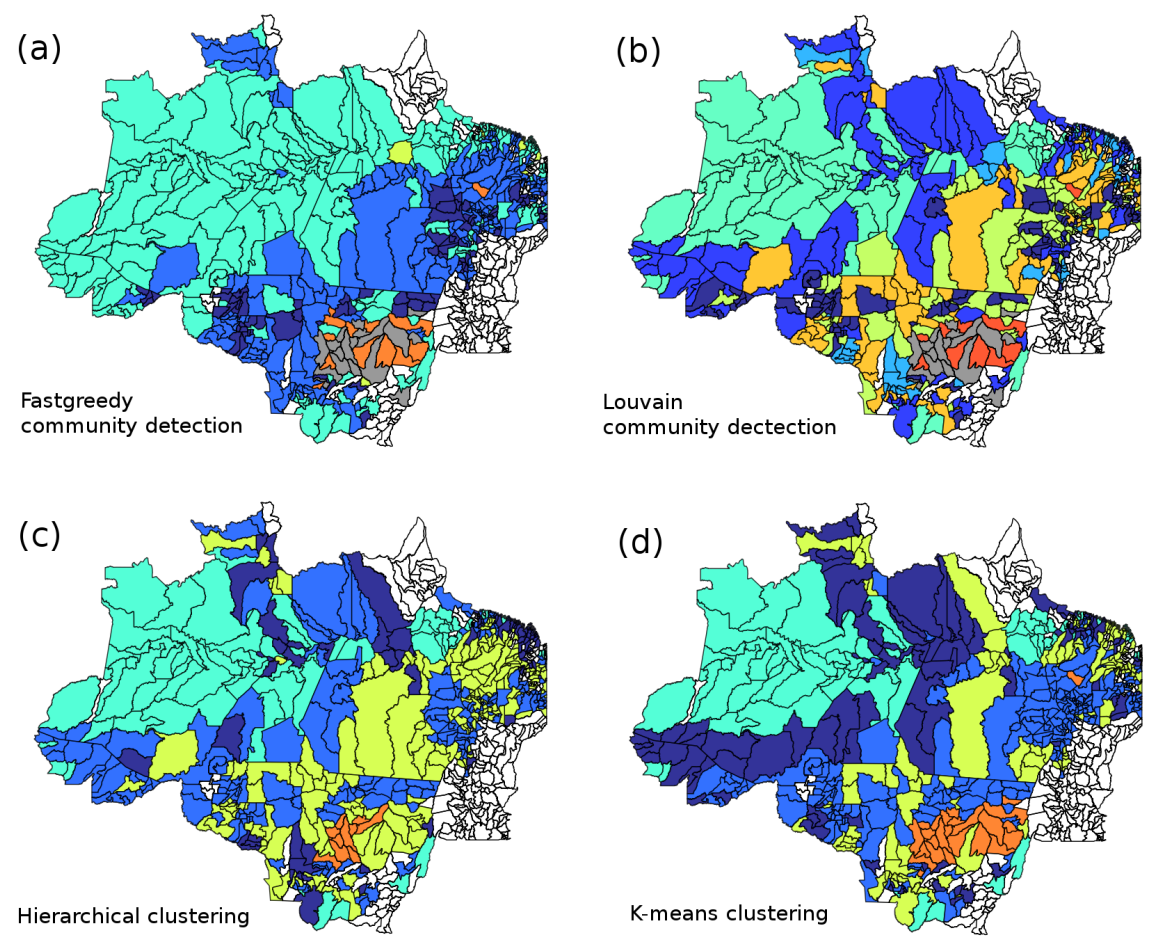

Figure S1. Comparison of network (a, b) and classical (c, d) clustering algorithms for transitions from secondary vegetation to other landuse classes between 2010 and 2012. The (arbitrary) colors indicate municipalities belonging to the same cluster. White regions lack data to estimate the transition matrix, grey regions are not connected to the similarity network. 

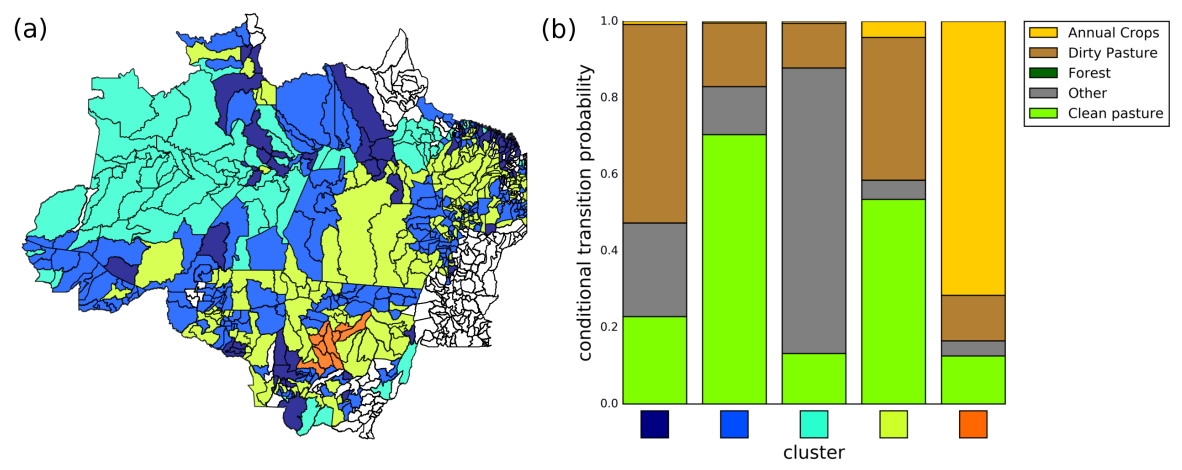

Figure S2. (a) Hierarchical clustering as in Fig. S1(c). (b) Corresponding cluster centroids showing the average conditional transition probabilities of the respective clusters.
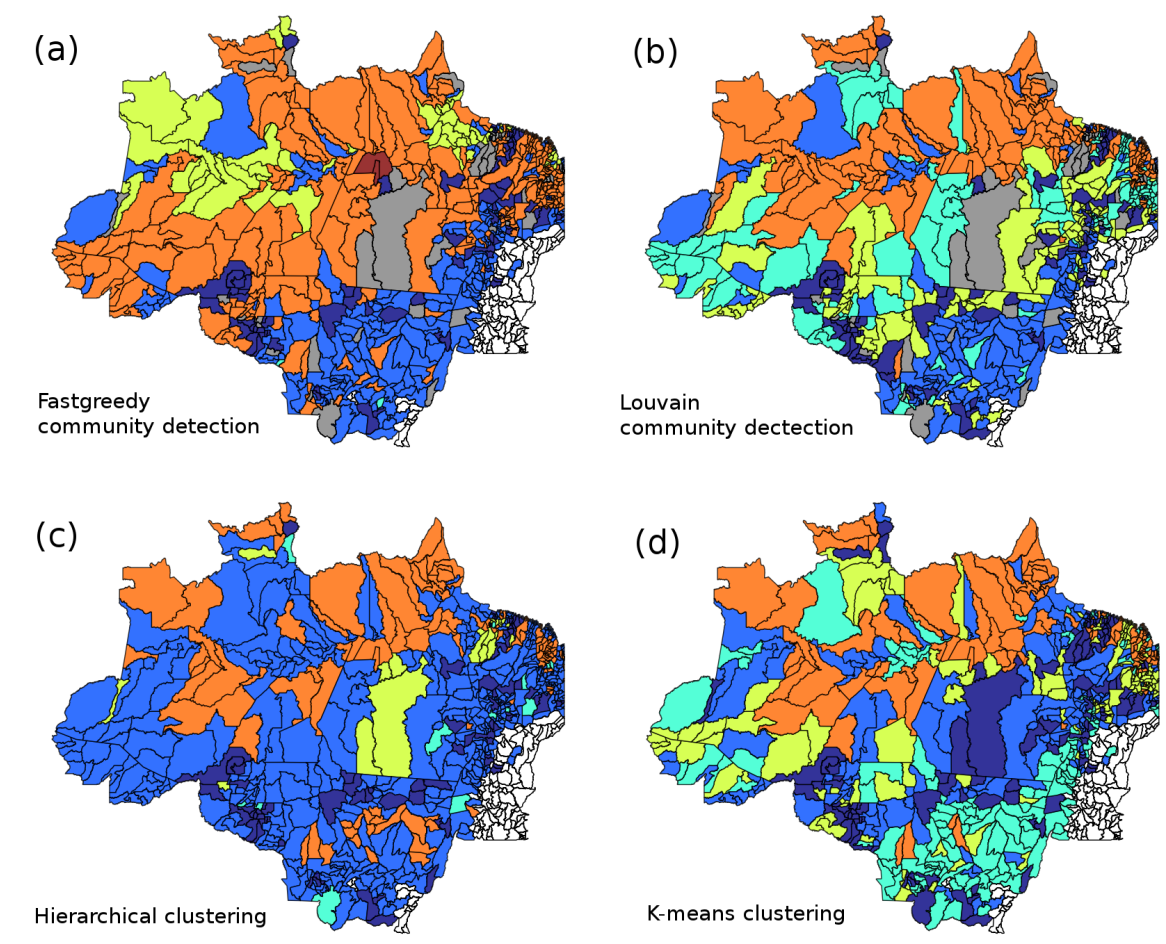

Figure S3. Comparison of network ( $a, b)$ and classical (c, d) clustering algorithms for the whole Markov matrices p between 2010 and 2012. Each cluster is visualized by one color. White regions lack data to estimate the transition matrix, grey regions are not connected to the similarity network. 

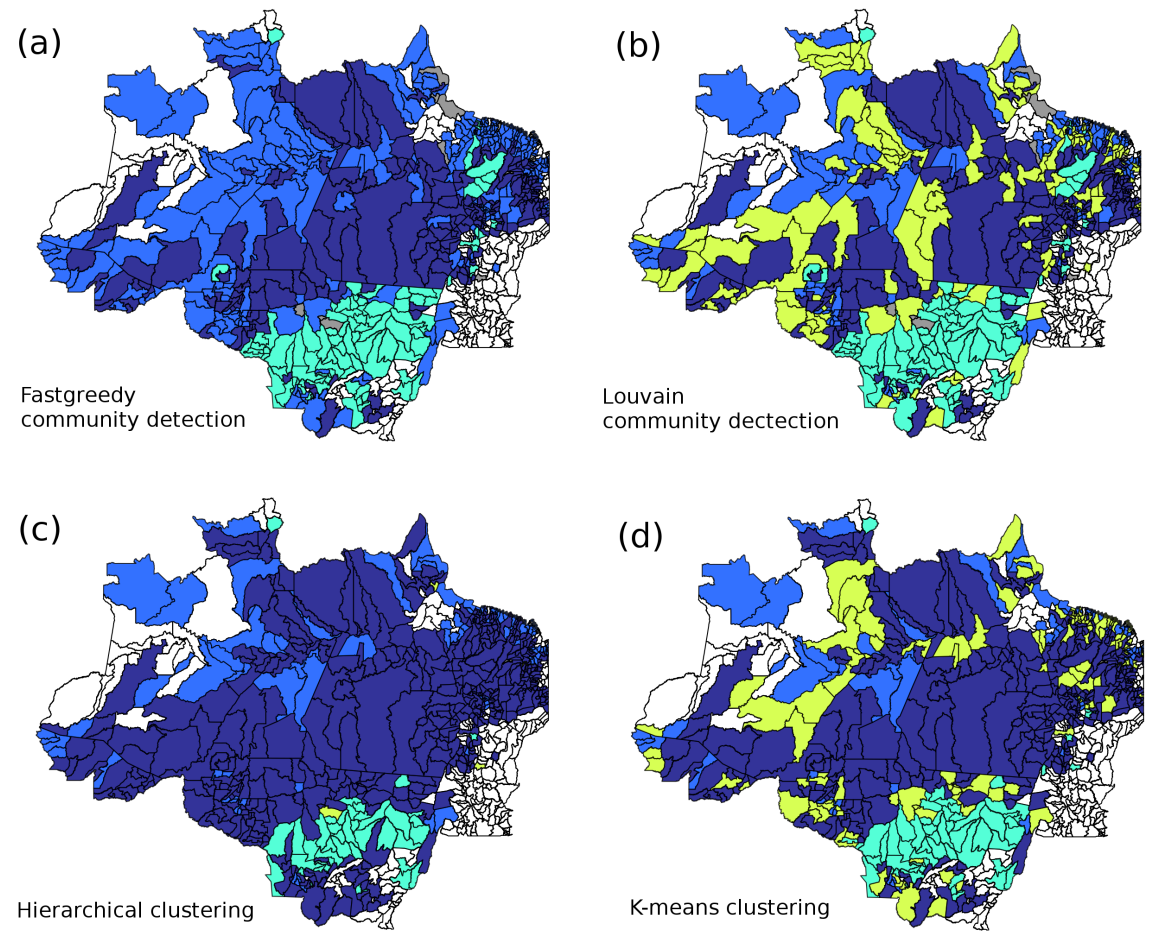

Figure S4. The same analysis as in Fig. 7 but with transitions between 2008 and 2010 . 

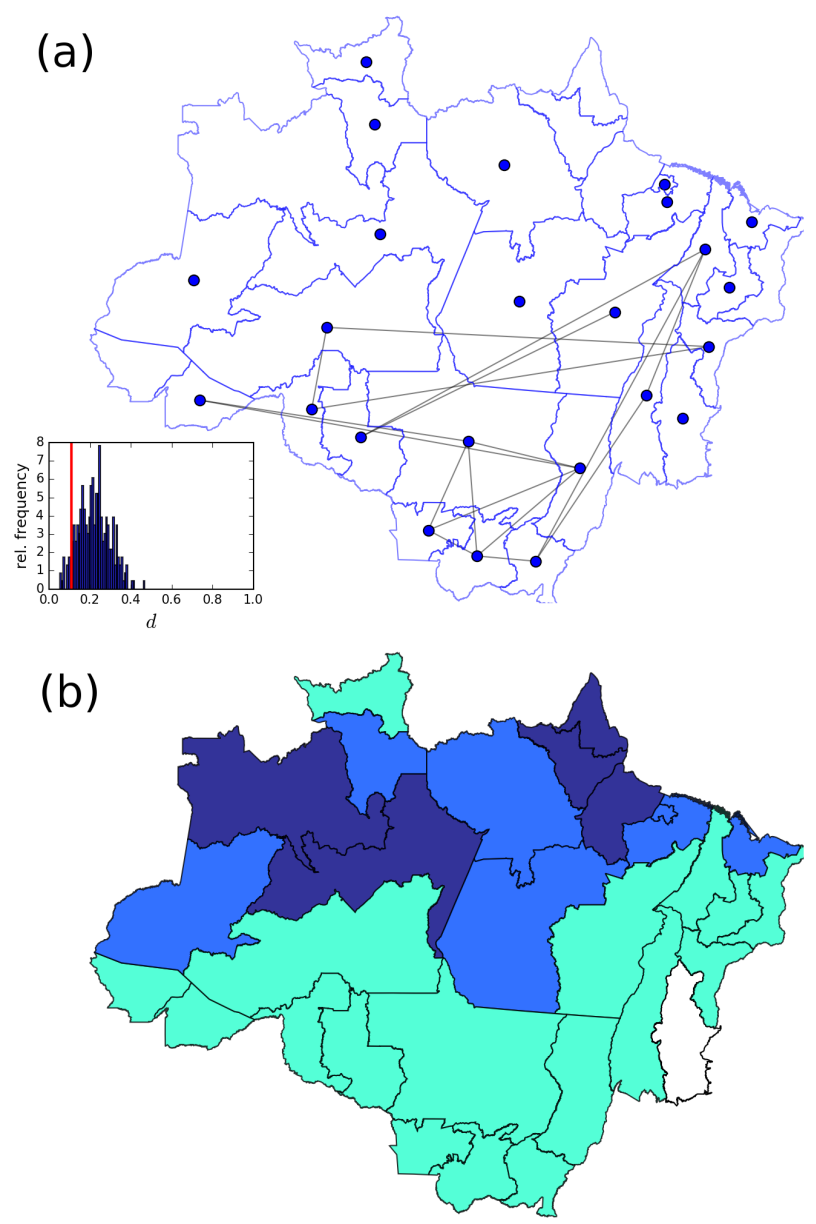

Figure S5. Illustration of the clustering with mesoregions as spatial partition for the whole Markov matrices p between 2010 and 2012 . (a) Similarity network: Because there are only few significant links and only few nodes connected to the network, the community detection is not feasible. (b) Result of the hierarchical clustering with 3 clusters. 